\begin{tabular}{|l|c|c|c|c|}
\hline $\begin{array}{l}\text { Cuadernos de Investigación Geográfica } \\
\text { Geographical Research Letters }\end{array}$ & 2019 & N $^{\circ} 45(1)$ & pp. 19-31 & eISSN 1697-9540 \\
\hline
\end{tabular}

\title{
A NEURO-SCIENTIFIC APPROACH TO ENVIRONMENT CARE
}

\author{
J. PUIGDEFÁBREGAS ${ }^{1}$, M. PÉREZ-GARCÍA ${ }^{2 *}$ \\ ${ }^{1}$ Estación Experimental de Zonas Aridas, Consejo Superior de Investigaciones Científicas (EEZA-CSIC), \\ 04120 La Cañada de San Urbano (Almería), Spain. \\ ${ }^{2}$ Centro de Investigación Mente, Cerebro y Comportamiento (CIMCYC). Universidad de Granada, Spain.
}

One Biosphere to Disturb, to Manage, to Cherish, to Understand, and to Love (Margalef, 1997)

\begin{abstract}
Grass-root feedback to public agencies' policies for coping with global change threats is poor and reactive. Concurrently, human population becomes more urban, isolated from nature and unable to take personal decisions about it. Therefore, helping societal involvement and proactive behavior towards nature is a crucial challenge nowadays. This paper intends to explore the role of emotions in support of a positive interaction in human/ environment systems, to assess their evolutionary changes and ways to eventually readdress its trend. For that purpose, the latest neuroscientific findings are applied to disentangle the nature impact on the human emotional system by comparing the present people's attitudes to those from pre-agrarian cultures. This knowledge allows drawing guidelines to improve people's concern to care for the environment.
\end{abstract}

\section{Una aproximación neuro-científica al cuidado del medio ambiente}

RESUMEN. La retroalimentación "grass-root" para las políticas de los organismos públicos que tienen como objetivo enfrentarse a las amenazas del cambio global es pobre y reactiva. Al mismo tiempo, la población humana se vuelve más urbana, aislada de la naturaleza e incapaz de tomar decisiones personales al respecto. Por lo tanto, ayudar a la participación social y al comportamiento proactivo hacia la naturaleza es en la actualidad un desafio crucial. Este artículo intenta explorar el papel de las emociones en apoyo de una interacción positiva entre los sistemas humanos/ambientales, con el objeto de evaluar sus cambios evolutivos y caminar finalmente hacia una reorientación de su tendencia. Con este propósito, se aplican las últimas conclusiones neurocientíficas para desentrañar el impacto de la naturaleza en el sistema emocional humano, comparando las actitudes de las personas actuales con las de las culturas preagrarias. Este conocimiento permite diseñar pautas que mejoren la preocupación de las personas por el cuidado del medio ambiente. 
Key words: Landscape, emotions, neuro-scientific approach, pre-agrarian cultures.

Palabras clave: Paisaje, emociones, aproximación neuro-científica, culturas pre-agrarias.

Received: 28 February 2018

Accepted: 2 May 2018

*Corresponding author: Miguel Pérez-García, Centro de Investigación Mente, Cerebro y Comportamiento (CIMCYC), Universidad de Granada, Spain.E-mail address: mperez@ugr.es

\section{In a nutshell}

(i) Emotions are sets of bodily signals activated by competent external stimuli, which help the cognitive system taking quick and safe decisions to resolveambiguous choices.

(ii) Basic emotions are processed in old brain structures, which are evolved adaptively to natural environments through landscape experiences, long before the first Homo sp. inhabited the savanna two million years ago.

(iii) Ontogeny mirrors evolution. Childs grown apart from nature cannot fully develop their basic emotional system.

(iv) Key cultural attitudes lost by contemporary humans are two: nature unconditionally supports everyone as an invaluable gift, and empathy extends like a brotherhood to all nature.

(v) Emotions are individual experiences that can be shared and cradled but not transferred.

The exponential increase of human pressure on Earth resources raises global environmental challenges that menace the sustainability of human life. This situation elicits international concern to increase our understanding of the involved processes to enable our capacity to develop mitigation and adaptation policies including public awareness.

During the last thirty years large international programs have been implemented to help worldwide responses to Global Change threats. The most significant are the International Geo-Biosphere Program (IGBP), the International Human DimensionsProgram (IHDP), the World Climate Research Program (WCRP) and DIVERSITAS, which are being integrated in the new Future Earth program. In addition, following the UN Rio Conference on the Environment (1992) three key UN Conventions entered inforce: Climate Change (UNCC), Biodiversity (UNBD) and Desertification and Drought (UNCCD). In 2000 the Millennium Ecosystems Assessment (ME) was launched and committed to provide a first worldwide evaluation of ecosystems.

The work done by these and other regional initiatives has been impressive. Significant achievements have been reached in terms of scientific progress, policy oriented recommendations, catalyzing global regulation compromises and public awareness. 
However, the engagement at the individual level beyond bearing "green" taxes is mostly reactive and rather poor compared to the aforementioned international effort. Large proportions of the population live in cities, isolated from nature areas. Therefore, there is a lack of grass-root proactive initiatives and discussions about policies issued from global organizations.

We think that such bottom up individual involvement in environment care is essential to complement coactive institutional initiatives. Fostering it is a crucial challenge nowadays. This paper aims at providing ground for a transdisciplinary contribution about how this problem can be specified and tangled out.

Our approach involves three steps: i) review the latest neuro-scientific findings concerning the emotional and cognitive interaction in decision making and its application to the human-environment system; ii) compare the attitudes reported from pre-agrarian hunter-gatherer cultures to ours and identifying in what we changed; iii) the outcomes of this exercise will enable drawing coarse policy lines to enhance people`s integral concern in the environment care.

\section{How decisions in the human/environment interaction are taken at the individual level}

The psychological ground of the relations between humans and their environment is mediated by, at least, the following psychological processes: attention and perception of environmental stimuli, emotional processing of those stimuli and decision making about the situation. The three altogether involve a continuous cognitive and emotional interaction that creates attitudes toward the environment (Fig. 1).

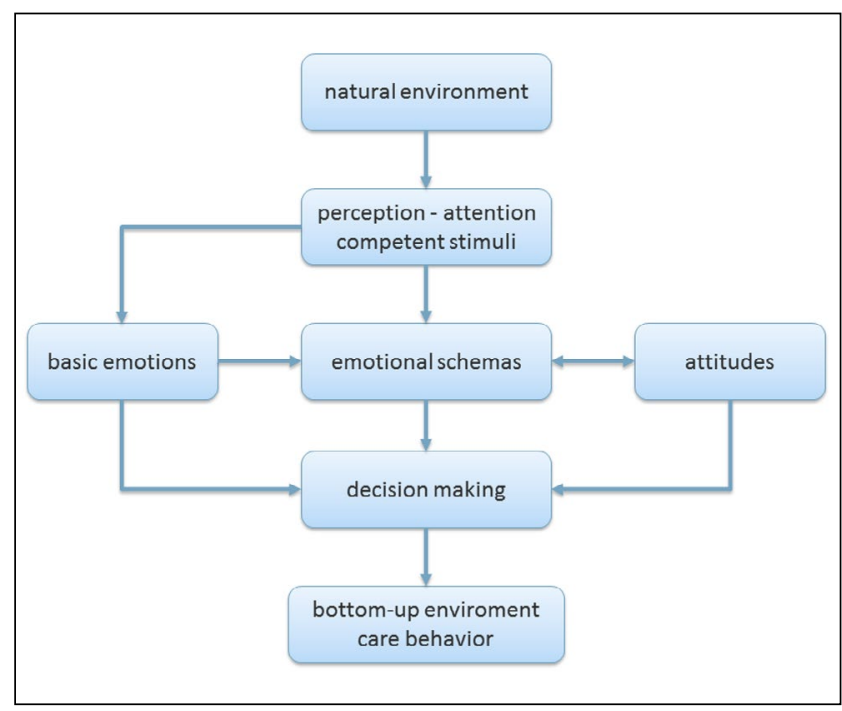

Figure 1. Structure of the environmental decision process. When natural environment (input) is perceived and attended, competent stimuli become screened to trigger emotional responses in form of basic emotions or emotional schemas, which feed the emergence of attitudes. Basic emotions, emotional schemas and attitudes influence the decision-making on environmental care behavior (output). 


\subsection{Attention and perception of environmental stimuli}

Attention is a complex cognitive process that involves alertness, spatial orientation and solving informational conflicts (Petersen and Posner, 2012). These three attentional networks are responsible of both sustained and selective attention (Tang et al., 2012). They support perception at various scales (Fig. 2) and enhance its integration in the landscape individual experience (Puigdefábregas and Pérez García, 2014). Figures 2, 3 and 4, are aquarelle paintings of Namibian landscapes by the late Christine Marais. Therefore, they are land perceptions and as such they were judged helpful to understand some of the ideas raised in this paper.

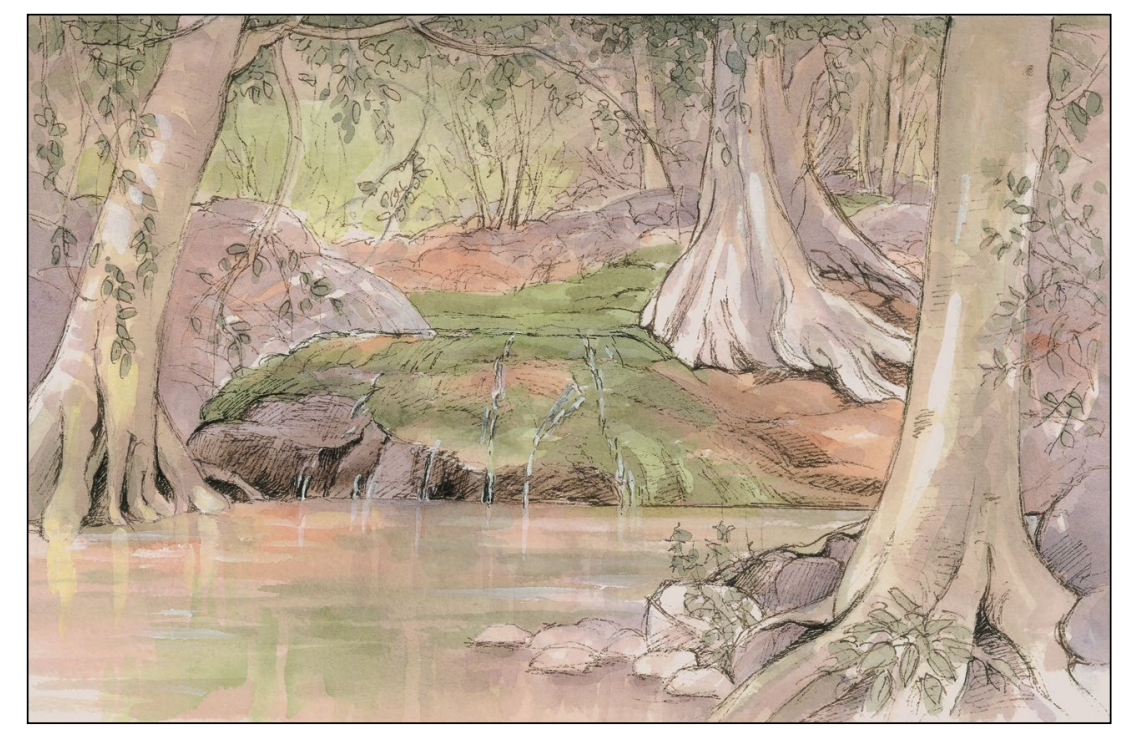

Figure 2. Multiscale attention in the Figure Tree Grove on the Farm Zebra River (Namibia). Note the loss of detail at the distance in the sustained attention, contrasting with the extreme discrimination of forms and colors in the selective attention to the foreplan spring. Aquarelle by C. Marais (by courtesy of family Marais).

Perception results from a subset of the whole range of stimuli that reach the subject at a particular moment. They are highlighted by attention as competent to raise emotions or to convey information to the cognitive system. Once filtered out in this stage, impacts of environment stimuli are managed by neural and symbolic processing. Such processing in turn evolves in adaptive suites to stress some traits of raw stimuli.

Neural processing has been investigated in visual perception (Wagermans et al., 2012a, 2012b) and relies on the high capacity of humans to distinguish spatial patterns. This means their ability to differentiate shapes of isolated objects from the ground textures (Fig. 3) (Zhang and Heydt, 2010; Bullier, 2001; Russell and Etienne-Cummings, 2012). Humans have also aninnate ability to evaluate distances 
and slopes of desired targets in a terrain scenario interms of the effort and risk of reaching them. Hills appear steeper and farther the rougher is their relief; distance to the ground viewed from the cliff edge increases with one's fear of falling down (Proffitt, 2006).

Symbolic processing may arise at the individual level from repeated landscape experience at the same place. In such cases, some features may be significant by associations to other owned experiences. By this way, an often visited territory becomes populated by symbols as a network that enables stable links to the emotional system. This facilitates some kind of understandable representation previous to action (Puigdefábregas and Pérez García, 2014).

\subsection{Emotions and emotional responses induced by landscape}

The large tradition of emotion research along the history of psychology provided several theories (Dixon, 2012), but they could not yield a theoretical frame till neuroscientific research was integrated to psychological and evolutionary models. According to Izard (2009), emotions are sets of bodily signals activated by competent external stimuli. They help the cognitive system taking quick and safe decisions to resolve ambiguous choices. Izard identified two kinds of emotions: basic emotions and emotion schemas, this distinction is of paramount operational relevance.

Basic emotions refer to affective processes generated by evolutionarily old brain systems upon sensing of an ecologically valid stimulus. Basic emotions can be positive or negative (Izard, 2009). The former are generally associated to interest and joy and are driving signals of 'going ahead'. The latter are sadness, anger, disgust and fear. They help survival in case of danger and they occur automatically in high intensity short time spans.

Emotion schemas consist of emotion and cognition continuously interacting events to influence mind and behavior. This dynamism enables emotion schemas acting as situation-specific factors or traits of temperament-personality, which allow special and powerful effects on self-regulation, perception, thought and actions (Izard, 2009).

Emotions have a critical role in decision making processes according to the Somatic Marker Theory (SMT) (Damasio, 1996). SMT may be considered a subset of emotion schemas that provide a framework for decision making in real-life scenarios. The main point of SMT is that decision-making is a process guided by emotions. By means of an emotional mechanism that highlights consequences of an action, SMT assists in the selection of an advantageous option before any action has been undertaken.

Historical narratives and traditional environmental psychology offer an invaluable material to test the aforementioned neuroscientific theories. Information on the emotional impact embedded in landscape can be tracked back to the early historical times around 4 millennia before present in Eurasia, as narratives (Puigdefábregas and Pérez García, 2014). Latter on it can be shown as quasi- 
mystical landscape paintings (Vermeer and Dutch school $17^{\text {th }}$ century; Barbizon in France or Olot in Spain schools in $19^{\text {th }}$ century). Down to present, such information is shown in landscape preferences (Kaplan, 1992) and landscape health restoration experiments (Hartig et al., 2011).

The first surprising conclusion is that though this information has been mostly attributed to cognitive activity (Kaplan, 1992) it expresses emotional schemas conveyed by landscape. Their underlying basic emotions are easily identified and they fit reasonably well to the latest neuroscientific findings. The most frequent basic emotions related to the natural environment are by large positive either concerned with interest or with joy (Puigdefábregas and Pérez García, 2014).

Associated to interest there are emotional schemas like admiration, mystery, diversity, luxuriance (Kaplan et al., 1989). Competent stimuli are characterized by being new and challenging to the subject and they are provided by the aforementioned combinations of spatial patterns, singular features and symbols, which call for exploration (Singh et al., 2008) (Fig. 3).

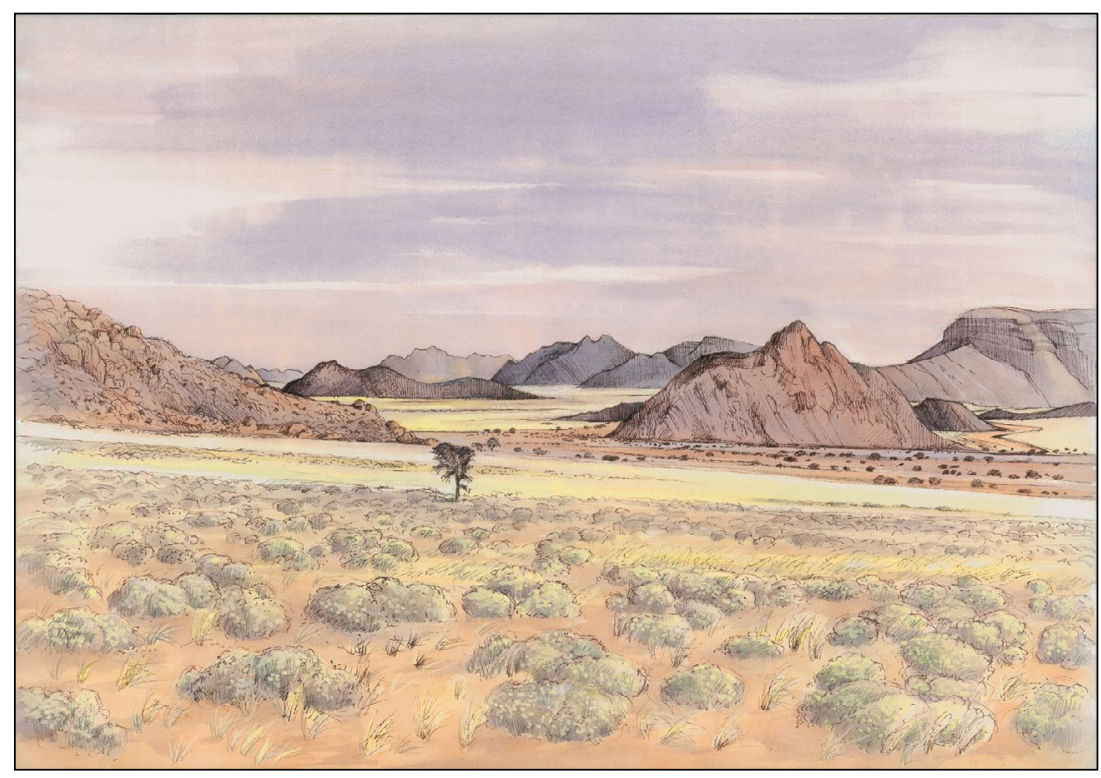

Figure 3. In the grassy eastern Namib plains, isolated features, such a tree and prominent inselbergs, make a coarse-grained landscape where desolation, loneliness, fear and curiosity call the traveler to go and see rather than settling and live. Aquarelle by C. Marais (by courtesy of family Marais).

Associated to joy there is a compact group of interrelated emotion schemas that support the feelings of security, in-home dwelling and unconditional acceptation.Common valid stimuli result from repeated contacts that allow the environment be coming familiar and understandable to the subject. Most of them are of the type of 'legible' structured 
spatial patterns (Singh et al., 2008). In a more rigorous neuroscientific language this means finer-structured spatial ranges (Fig. 4).

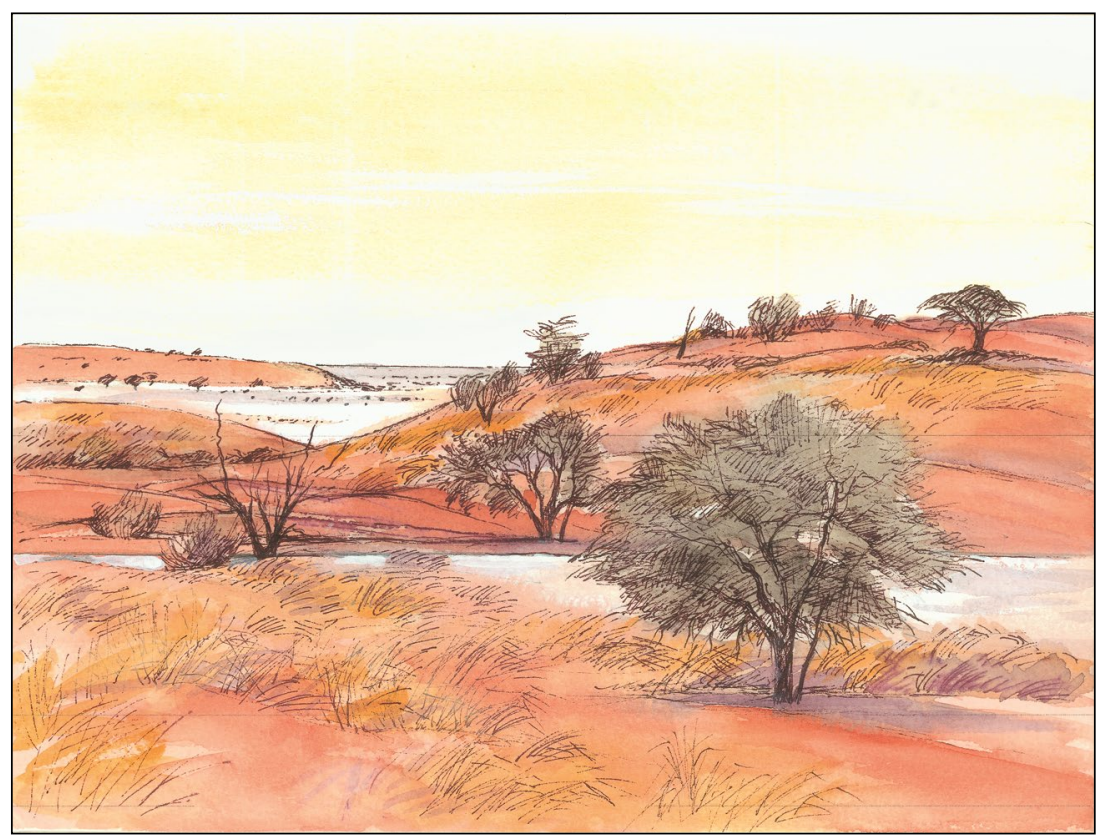

Figure 4. Kalahari savanna woodlands and grasslands in old fixed sand dunes. Note the finer grained landscape compared to Figure 3, which looks more habitable and raises joy and home dwelling basic emotion. Aquarelle by C. Marais (by courtesy of family Marais).

Kaplan's landscape preference model assumes a cognitive underlying process in which preferred scenes should have two properties: involvement (exploration drive) and understanding (sense making) (Kaplan, 1988). Both properties are 'latent' in the sense that they emerge from statistical associations with perceived qualifications in the choice experiments. Such qualifications were labeled as diversity/complexity and mystery for involvement, and coherence-legibility for understanding (Table1).

Table 1. Kaplan's landscape preference model.

\begin{tabular}{|l|l|l|}
\hline Level of interpretation & Making sense & Involvement \\
\hline The visual array & Coherence & Complexity \\
\hline Three-Dimensional Space & Legibillity & Mystery \\
\hline
\end{tabular}

The road Kaplan opened to environmental psychology can be better understood by current neuroscientific findings but also it provides them with invaluable tests. Kaplan's latent properties, involvement and understanding, are unveiled to become the two recognized positive basic emotions, interest and joy, in the landscape context. Their 
qualifications should be interpreted not as perceptions but as emotion schemas derived from the interaction of basic emotions with cognition.

Negative basic emotions are less frequent but more intense. This is particularly true in the case of fear, which somatic markers are mostly associated to catastrophic events, big predators, poisonous or harmful animals and to uncertain harm risks (darkness inforest floors, in caves). Sadness could be associated to the subject exclusion from his indwelling land either by environmental or socio-politic drivers (Tschakert et al., 2013). Experiments of refined landscape preferences by introducing changes in the scenes (Cloquell-Ballester et al., 2012) show that sadness may be also induced by intrusion of industrial or urban elements, loss of symbolic features, damages to wildlife and land degradation. In extreme cases the aforementioned authors report that anger to the responsible or disgust might be elicited by spoiled, eutrophication-affected or degraded landscapes.

However, as far as we know, only one neuroscientific study has evaluated the emotional valence of natural stimuli using neuroimaging. Kim et al. (2010) found that when participants were exposed to pictures of nature they activated the brain areas related with positive emotional processing but not when urban pictures were shown.

\section{From emotion and decision making to personal and people attitudes}

There is a consensus in that developing individual and people attitudes related to the environment requires evolving from phenomenal to reflective-reportable consciences of the underlying emotions, and this increases dramatically with speaking capacity (Izard, 2009). However, there is also wide empirical evidence that emotions cannot be transferred but they can only be shared (Izard, 2009). Speaking capacity of describing emotions enables sharing them among those who have already experienced them, and hence, they are able to recognize them. This is of course an efficient but slow way to spread emotions, which has been followed since millennia.

There is an alternative approach to speed emotions sharing, which is also very old and still widespread today: the use of emotion carriers. That is using easily shared emotions through music, singing, dancing, paintings, poetry, as platforms to share target emotions within a group.

Anyhow, emotions sharing may happen in our environment context, it emerges from two sources that provide the emotional stuff to be shared: one spreads bottom up pushed by the evolution of empathy; the other works top down pushed by the symbolic development. Likely both converge into group and society emotion carrier activities.

\subsection{Empathy with nature}

Basic animal empathy constitutes a safeguard against con-specific predation. It creates a special kind of relationship that enables a physiological transmission of one creature's feeling to another, as it is appearing to the latter as itself (Langer, 1967/1982). It depends mainly on neurophysiological response systems that happen instantaneously 
(Hoffman, 2000). This kind of empathy evolved long before human evolution produced language and its accompanying cognitive prowess. However, there is evidence that humans have expanded this empathy to other animals and beings of their environment in a kind of brotherhood (Arsenyev, 1923/2004). We claim this expanded empathy with nature as the main attentional background for sharing emotions related to the environment.

\subsection{Developing networks of symbols}

Symbolic qualification as aforementioned is a very efficient way for bottom up sharing landscape emotions by creating spatial networks of symbols. There are other cultural, religious or political actors that also contribute to top down populating landscapes with symbols. These allow sharing emotions as well, though their links with real land and people are often weaker.

\section{The evolutionary perspective}

Our neuro-scientific understanding of the human-environment interactions cannot be complete without an evolutionary perspective. Human lineage (genus Homo) can be traced back to two million years ago. During this time, our cerebral mechanisms of perception-attention, emotion, decision making and attitudes evolved interacting with wild environments in gatherer cultures. The Neolithic transition to a producer agrarian metaphor happened only around teen thousand years ago. Though dramatic cultural changes might trigger this event, there is still too short time to yield brain significant modifications. Therefore, any operational knowledge of our emotional relation with environment needs to feed into our ancestor gatherer societies.

\subsection{Main features of the emotional relations with environmentof gatherer societies}

(i) Brain structures for somatic emotion processing and behavior guidance evolved in a long period, much longer than the elapsed since human's differentiation time (Damasio, 1996). This is indicated by their localization in the oldest parts of the brain like the hypothalamus, the brain stem, or the amygdala. This fact also stresses the current relevance of natural environments in eliciting emotion schemas today.

(ii) Emotion feelings interacting with cognition in the decision process requires some neural persistence and selective attention to enable motivation (Izard, 2009). Such conditions should provide an emotional-cognition baseline to perform complex gatherer activities and to grow empathy and symbolic structures. The appearance of speech dramatically accelerated these processes, namely by increasing the residence time of emotions and perceptions in the brain (Izard, 2009).

(iii) The advanced quality of space perception features in humans compared with the rest of mammals, suggests a relatively late adaptive evolution of a 
biped already living in savannas, steppes or open spaces. These endowments allowed gatherers building mind environment constructs that enabled them working at a big range of scales and efficient circulation across land. As a side effect, even more significant at the long term, we suggest that these perception qualities made possible symbolic evolution, identification and comparison of shapes with missing data, intuition and creativity (Salk, 1985; Puigdefábregas and Pérez García, 2014).

(iv) There is a striking worldwide homogeneity in the paleontological record of gatherers and their today survivors around the world, which provides archaeological evidence of a common background (Johnson and Earle, 2000). This concerns also main emotional schemas and their underlying basic emotions shared to build cultural attitudes. They may be observed in the following aspects:

(a) People consider themselves as "suckling's" of their "indwelling" land, which is their mother who unconditionally provides them with all their needs (Ingold 2000, Nurit Bird-David 1990). Those old basic emotion systems appear today at the early childhood (Izard, 2009) and they are progressively buried with age (González Bernaldez et al., 1987) by the inputs from the prevailing urban symbolic cultural world. However, they may reappear when the individual reacts from its own 'self' as shown in the aforesaid preference experiments (Cloquell-Ballester et $a l .$, 2012). Our gatherer ancestors and their survivors kept this child basic emotion system till advanced ages according their aforementioned cultural attitudes.

(b) That suckling 'feeling' has two mirror major consequences. A first one is a widespread brotherhood or secondary empathy, grown by cognitive emotional interaction, which enables one taking the perspective of another and sharing emotions with him (Izard, 2009). A second one is the so called gift economy (Bird-David, 1990) benefits from the environment are invaluable and attain everybody. They are gifts, and therefore their mirror social attitude is acting alike: goods are given to others as gifts.

(c) Such attitudes are better expressed in low density populations inhabiting large areas, with scattered resources and without traits of domestication (Nurit Bird-David, 1990); on the contrary, they don't happen in dense populations concentrated in small resource-rich areas, mostly with some familiar agriculture (Johnson and Earle, 2000). The latter need big effort to defend resources from neighbors' settlement.

Emotion sharing by symbolic development, dances, storytelling, healing activities and community decision assemblies were the main ways to build cultural attitudes (Biesele, 1978). 


\section{Concluding remarks}

Late neuro-scientific research enables substantial advances to our knowledge on the psychological processes involved in the interaction between humans and their environment. First, it allows integrating the knowledge generated by different independent research lines in a common theoretical frame (Hartig et al., 2011). Second, it helps identifying research gaps in the understanding of human-environment interactions. Third, it provides a baseline for stimulating individual and social attitudes to support programs concerned with global change challenges. Though consolidating this baseline requires more research, some key assertions already emerge:

(i) Involving individuals and societies in decisions concerning the environment requires raising emotions, but emotions can't be transferred, they only can be shared or cradled to be born.

(ii) The two attitudes related to the environment that we should at least recover from our gatherer ancestors are empathy with natural environment and gift, invaluable, consideration of its goods.

(iii) Concerning landscape feelings, ontogeny mirrors evolution. Acting on child stages is likely more successful.

(iv) Spreading urbanization, particularly megacities, buries citizens in a more symbolic world isolated from their own natural environment and feelings.

(v) Bottom up initiatives, like Land-Earth Stewardship and Civic Ecology Groups (Krasny and Tidball, 2012) might cradle emotion sharing in support of community decisions and global policy strategies concerning the environment.

\section{References}

Arsenyev, V. 1923/2004. Dersu Uzalá. University Press of the Pacific. Honolulu.

Biesele, M. 1978. Sapience and scarce resources: Communication systems of the !Kung and other foragers. Social Science Information 17 (6), 921-947 https://doi. org/10.1177/053901847801700607.

Bird-David, N. 1990. The giving environment: Another perspective on the economic system of gatherer-hunters. Current Anthropology 31 (2), 189-196. https://doi.org/10.1086/203825.

Bullier, J. 2001. Integrated model of visual processing. Brain Research Reviews 36 (2-3), 96-107. https://doi.org/10.1016/S0165-0173(01)00085-6.

Cloquell-Ballester, V.A., Torres-Sibille, A.C., Cloquell-Ballester, V.A., Santamarina-Siurana M.C. 2012. Human alteration of the rural landscape: Variations in visual perception. Environmental Assessment Review 32, 50-60. https://doi.org/10.1016/j.eiar.2011.03.002.

Damasio, A. 1996.The somatic marker hypothesis and the possible functions of the prefrontal cortex. Philosophical Transactions of the Royal Society B: Biological Sciences 351, 1413 1420. https://doi.org/10.1098/rstb.1996.0125.

Dixon, T. 2012. "Emotion": The history of a keyword in crisis. Emotion Review 4 (4), 338-334. https://doi.org/10.1177/1754073912445814. 
González Bernáldez, F., Gallardo, D., Abello, R.P. 1987. Children's landscape preferences: From rejection to attraction. Journal of Environmental Psychology 7 (2), 169-176. https://doi. org/10.1016/S0272-4944(87)80024-5.

Hartig, T., van der Berg, A.E., Hagerhall, C.M., Tomalak, M., Bauer, N., Hansmann, R., Ojala, A., Syngollitou, E., Carrus, G., van der Herzele, A., Bell, S., Camilleri Podesta, M.T., Waaseth, G. 2011. Health benefits of nature experience: psychological, social and cultural processes. In: K. Nilsson, M. Sangster, C. Gallis, T. Hartig, S. de Vries, K. Seeland, J. Schipperijn (Eds.), Forests, Trees and Human Health, Springer Science, 427 pp. htpps://doi.org/10.1007/978-90481-9806-1_5.

Hoffman, M.L. 2000. Empathy and moral development: Implications for caring and justice. Cambrige Univesity Press, New York, 325 pp.

Ingold, T. 2000. The perception of the environment. Routledge, London, 465 pp.

Izard, C. 2009. Emotion theory and research highlights, unanswered questions and emerging issues. Annual Review of Psychology 60, 1-25. https://doi.org/10.1146/annurev. psych.60.110707.163539.

Johnson, A.W., Earle, T. 2000. The evolution of human societies. Stanford University Press, 440 pp.

Kaplan, R., Kaplan, S., Brown, T. 1989. Environmental preference: A comparison of four models of predictors. Environment and Behavior 21 (5), 509-530. https://doi. org/10.1177/0013916589215001.

Kaplan, S. 1988. Perception and landscape: conceptions and misconceptions. In: J.L. Nasar (Ed.), Environmental aesthetics: Theory, research, and application, Cambridge University Press, pp. 45-55.

Kim, T. H., Jeong, G.W., Baek, H.S., Kim, G.W., Sundaram, T., Kang, H.K., Lee, S.W., Kim, H.J., Song, J.K. 2010. Human brain activation in response to visual stimulation with rural and urban scenery pictures: A functional magnetic resonance imaging study. Science of the Total Environment 408 (12), 2600-2607. https://doi.org/10.1016/j.scitotenv.2010.02.025.

Krasny, M.E., Tidball, K.G. 2012. Civic Ecology: a pathway for Earth Stewardship in cities. Frontiers in Ecology of the Environment 10 (5), 267-273. https://doi.org/10.1890/110230.

Langer, S.K. 1967/1982. Mind: An essay of human feeling. Johns Hopkins University Press. Baltimore, $422 \mathrm{pp}$.

Margalef, R. 1997. Our Biosphere. In: O. Kinne (Ed.), Excellence in Ecology. Ecology Institute, Olendorf/Luhe. https://doi.org/10.1002/iroh.19970820411.

Petersen, S.E., Posner, M.I. 2012. The attention system of the human brain: 20 years after. Annual Review of Neuroscience 35, 73-89. https://doi.org/10.1146/annurev-neuro-062111-150525.

Proffitt, D.R. 2006. Embodied perception and the economy of action. Perspectives on Psychological Science 1 (2). http://doi.org/10.1111/j.1745-6916.2006.00008.x.

Puigdefábregas, J., Pérez García, M. 2014. Landscape as a central experience in the interaction between humans and their natural environment. In: J. Arnáez, P. González-Sampériz, T. Lasanta, B. Valero-Garcés, B. (Eds.), Geología, cambio ambiental y paisaje: Homenaje al Prof. J. M. García Ruiz. Universidad de la Rioja, Logroño, pp. 451-460.

Russell, A., Etienne-Cummings, R. 2012. Perceptual organization, attention and object recognition: closing the loop. $46^{\text {th }}$ Annual Conference on Information Sciences and Systems (CISS), IEEE, Princeton. https://doi/org/10.1109/CISS.2012.6310919.

Salk, J. 1985.The Anatomy of Reality. Merging of Intuition and Reality. Praeger Publishers Inc., New York, pp. 1-160.

Singh, S.N., Donavan, D.T., Mishra, S., Little, T.D. 2008. The latent structure of landscape perception: A mean and covariance structure modeling approach. Journal of Environmental Psychology 28 (4), 339-352. https://doi.org/10.1016/j.jenvp.2008.03.004. 
Tang, Y.Y., Rothbart, M.K., Posner, M.I. 2012. Neural correlates of establishing, maintaining and switching brain states. Trends in Cognitive Sciences 16 (6), 330-337. https://doi. org/10.1016/j.tics.2012.05.001.

Tschakert, P., Tutu, R., Alcaro, A. 2013. Embodied experiences of environmental and climatic changes in landscapes everyday life in Ghana. Emotion, Space and Society 7, 13-25. https:// doi.org/10.1016/j.emospa.2011.11.001.

Wagemans, J., Elder, J.H., Kubov, S., Palme, S.E., Mary, A., Peterson, M.A., Singh, M., von der Heydt, R. 2012a. A century of gestalt psychology in visual perception I. Perceptual grouping and figure-ground organization. Psychological Bulletin 138 (6), 1172-1217. https://doi. org/10.1037/a0029333.

Wagemans, J., Feldman, J., Gepshtein, S., Kimchi, R., Pomerantz, J.R, van der Helm, P.A., van Leeuwen, C. 2012b. A century of gestalt psychology in visual perception II. Conceptual and theoretical foundations. Psychological Bulletin 138 (6), 1218-1252. https://doi.org/10.1037/ a0029334.

Zhang, N.R., von der Heydt, R. 2010. Analysis of the context integration mechanisms underlying figure-ground organization in the visual cortex. The Journal of Neuroscience 30 (19), 64826496. https://doi.org/10.1523/JNEUROSCI.5168-09.201. 